\title{
衛星を利用した自己同期方式ADSの伝送特性解析
}

\author{
住谷 泰人*・石出

\section{Analysis of Self-synchronized Automatic Dependent Surveillance using Satellite}

明*

\section{Yasuto SUMIYA and Akira ISHIDE}

\begin{abstract}
Satellite-based Automatic Dependent Surveillance (ADS) using a polling protocol can reduce a transmission delay greatly compared with the conventional ADS using the satellite data communication that meets ICAO Aeronautical Mobile Satellite Services (AMSS) standards. Although the polling protocol shows excellent performances, it still has some shortcomings. In the polling ADS, an ADS report request must be transmitted for every ADS report transmission, and the guard time between successive ADS reports must be larger than the maximum difference of round-trip times between a satellite and an Aircraft Earth Station(AES). These cause some deterioration in transmission efficiency of the channels. This report describes self-synchronized ADS using a satellite. It improves the transmission efficiency over the channels of both ADS report request and ADS report transmissions. Since any modulation and coding schemes can be used with this protocol, it can also be applied to future aeronautical satellite communication systems.
\end{abstract}

Keywords : Satellite Communication, Air Traffic Control, Data Communication, Automatic Dependent Surveillance

キーワード: 衛星通信，航空管制，デー夕通信，自動位置情報・伝送機能

\section{1. まえがき}

洋上における航空管制では，これまで主に，航空 機の位置通報に短波の無線電話を用いてきた。しか し, 北太平洋航空路等の一部の航空路では, 衛星を 利用した音声・データ通信である ADS(Automatic Dependent Surveillance:自動位置情報伝送・監視機能) が試行運用され，2006 年 7 月 6 日からは正式運用が なされている。ADS は航空機に搭載された航法装置 より取得される位置情報をもとに，自動的かつ定期 的に地上の航空管制センタにデータ通信を行い，航 空機の位置を監視できる。ADSは，ICAO (International Civil Aviation Organization:国際民間航
空機関)の航空衛星通信技術標準(AMSS SARPs： Aeronautical Mobile Satellite Services Standards and Recommended Practices)に基づき，そのプロトコルに 起因して伝送遅延時間が増加する問題があり, 航空 機が増加した場合等に伝送遅延時間が大きくなる問 題を抱えていた。この問題を克服するため, 当所で は，簡易なプロトコルで伝送遅延時間を短縮できる

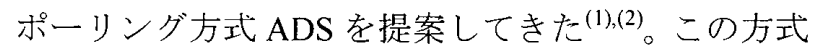
は，伝送遅延時間が 1，2 秒程度で斉む長所がある。 しかし ADS の送信回線数と同数の送信要求伝送用 回線が必要である問題や，高速な伝送速度において ガードタイムの影響が大きくなる問題等があった。

* 正会員 独立行政法人電子航法研究所（产182-0012 東京都調布市深大寺東町 7-42-23）

sumiya@enri.go.jp, ishide@enri.go.jp 
このため，これらの問題を改善できる自己同期方式 ADS を検討してきた ${ }^{(3)(4)}$ 。

本稿では，衛星を利用したポーリング方式 ADS や従来の ADS 伝送方式と比較した自己同期方式 ADS の概念と概要を述べる。また, 当研究所の所有 するICAO AMSS SARPS 準拠の数值解析シミュレー 夕を改修し, 自己同期方式 ADS について伝送特性解 析を行った結果も報告する。

\section{ADS}

\section{1 現用 ADS}

現用 ADS に代表される航空衛星通信では，Fig.1 に示すとおり, P, R, Tの 3 種類のチャネルで, ATN

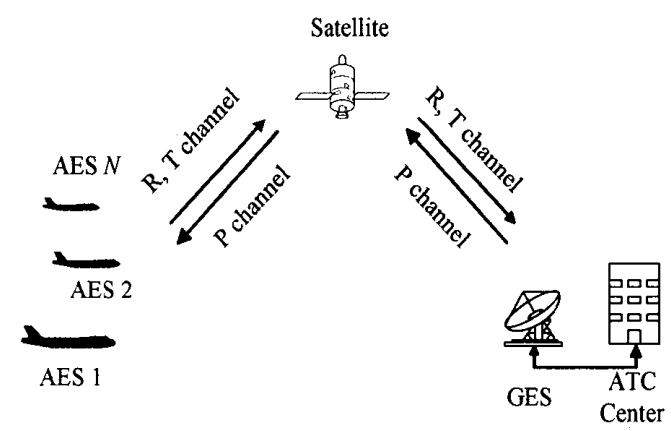

Fig.1 Configuration of Current Aeronautical Satellite Link

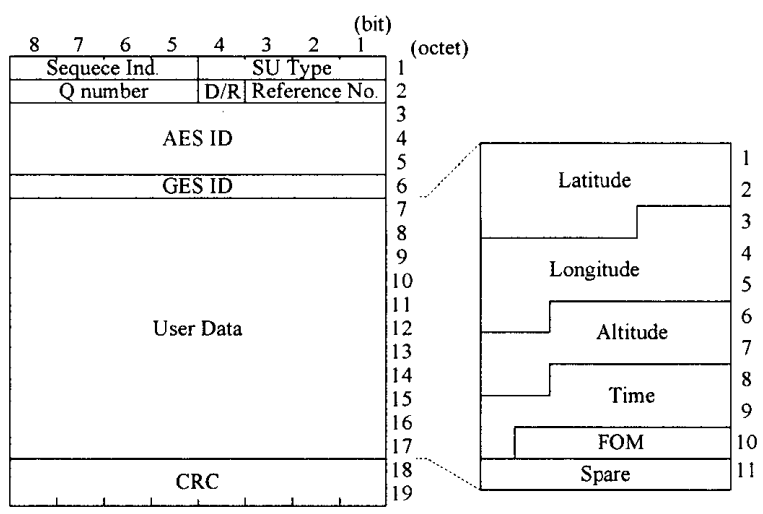

Fig.2 Example of ADS Report Format

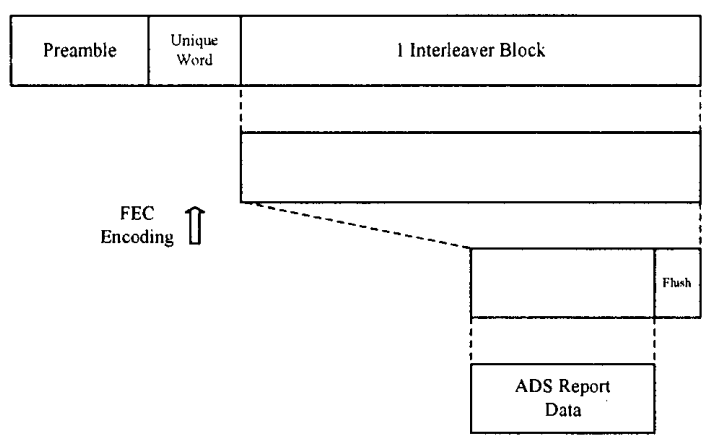

Fig.3 Burst Signal Format of ADS report

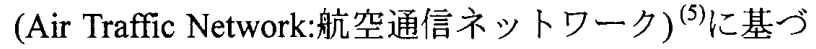
く通信を想定している。Pチャネルは, ATC Center(Air Traffic Control Center:管制センタ)から GES(Ground Earth Station:航空地球局), 衛星(Satellite) を経由し, AES(Aircraft Earth Station:航空機地球局) への通信に用いられ, 各 AES 宛のデータを ATC Center から受け取った時間順に基づき送信する時分 割多重(TDM:Time Division Multiplex)方式が用いら れる。 R チャネルや T チャネルは逆に, AESから衛 星, GES を経由し ATC Centerへの通信に用いられる。 R チャネルは，データをいつでも送信できるランダ ムアクセス方式である。これに対し，Tチャネルは， 送信スロットの割り当てを受けてデータを送信する 予約時分割多元接続方式(TDMA：Time Division Multiple Access)が用いられる。チャネル利用の違い はデータ長に基づいでいる。 $\mathrm{R}$ チャネルは 33octet 以下のデータの場合に用いられ，33octet よりも大き なデータ長では Tチャネルが用いられる。なお，こ こで用いた octet とは，8ビットに相当するデータの ことである。また, GES 経由での ATC Center と AES の通信回線のうち, GES と ATC Center 間は商用の専 用回線である。本稿では，GES と AES 間を対象と しているため, 今後, ATC Center と AES 間の通信は, GES と AES 間の通信上して述べることがある。

現用の航空衛星通信では，ログオンと呼ばれる事 前通信手続により,データ通信を始める AES のアド レスが GES に登録され，ADS も含めてすべてのデ 一夕通信が可能となる。現用 ADS では, 緯度, 経度, 高度, 時刻等の伝送が, Fig. 2 に示すフォーマットで 構成される基本 ADS グループで送信される。なお, このフォーマットは，ICAO AMSS SARPs に規定さ れた SU (Signal Unit:パケットの最小単位) から流用 している。Fig.2 において, CRC(Cyclic Redundancy Check: 巡回圥長性検查ビット)とは SU 内の誤りの 有無を判定するために用いられ，誤りがあった場合 にはその SU(この場合は ADS レポート)が破棄され る。Fig.3に ADS レボートのバースト信号のフォー マット例を示す。変復調方式, 符号化方式として, ICAO AMSS SARPs に規定された OQPSK+畳込符号 ／ビタビ復号(符号化率 1/2, 拘束長 7)を流用した。 これにより, 衛星回線を伝送するデータ長は基本 ADS グループ 11 octet に各種通信制御用のヘッダが 付加されて 223 octet になる(5)。このデータ長から， ADS レポートはTチャネルにより送信される。Tチ ヤネルのデータの通信シーケンスを Fig.4 に示す。 まず，AESから衛星を経由して，GESに，Rチャネ ルでスロットの予約を行う。 GES では，Tチャネル 


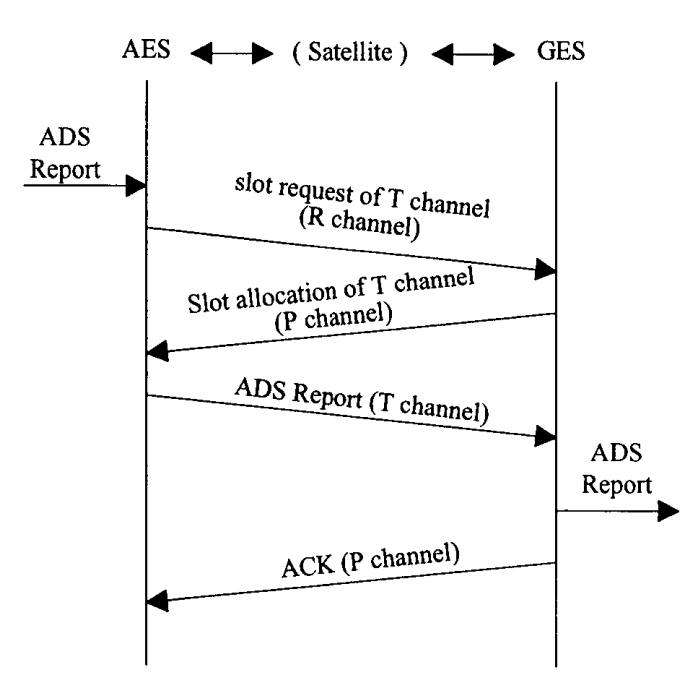

Fig.4 Data Sequence of T-channel

におけるスロット割り当てのためのテーブルに基づ いて，この通信専用の $\mathrm{T}$ チャネルのスロットを予約 し，予約情報を P チャネルにより，GES から衛星経 由で AES に通知する。AES ではこの通知内容に基 づき，予約されたスロットにおいて $\mathrm{T}$ チャネルで AES から衛星経由で GES にデータ通信する。GES では通信が正しく行われたか行われないかに基づい て, AES に対し P チャネルを用いて衛星経由で通知 確認のために，ACK を応答する。なお，指定された 時間内に ACK が受信されない場合は, ランダムな 時間だけ待ってデータを再送する。以上のプロセス を繰り返し，一定の時間間隔で各航空機の位置を地 上側で監視できる。このとき，航空機の監視精度は 位置情報の精度と更新間隔に依存することになる。 現在, 航空衛星通信を利用している北太平洋航空路 での ADS の更新間隔は, 27 分である。これに対し, 国内の航空機の監視にはSSR (二次監視レーダ)を用 いているため，更新間隔は 10 秒である。将来的に， 航空衛星通信を国内の航空機の監視に利用すること を想定した場合，国内の航空機の監視精度相当を考 慮する必要があるが， Tチャネルを用いる現用の方 式では, 10 秒の伝送間隔での監視は困難である。

\section{2 ポーリング方式 ADS}

前節の現用 ADS の問題点を解決するため, 当所で は, 種々の方式の ADS を提案してきている。このう ち，ポーリング方式 ADS の概念図を Fig.5 に示す。 なお，ポーリング方式 ADS でも現用 ADS 同様のロ グオンが実施されているものと仮定する。ポーリン グ方式 ADS では，まずATC Center から GESを介し て衛星のスポットビーム内の各 AES に順番に ADS レポート送信要求を送る。各 AES はこの送信要求に

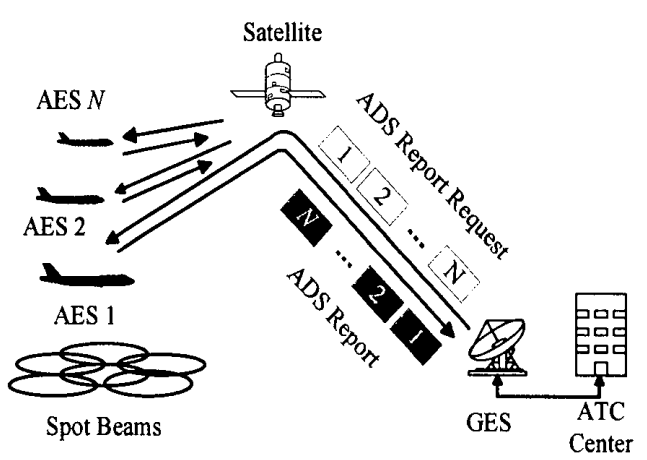

Fig.5 Concept of Polling ADS

応答して最新の位置情報をもとにした ADS レポー トを作成し，衛星経由で GES に送信する。GES で はADSレポートを受信すると,誤りがなければATC Center に送り，誤りがあれば破棄する(3)。このプロ セスを繰り返すことで，プロセスの繰り返し周期に 相当する一定の伝送間隔，例之ば伝送速度 $10.5 \mathrm{kbps}$ で 10 秒以下で各 AES の位置を ATC Center で監視で きる。

ポーリング方式 ADS は, 衛星は原理的に静止衛星 または周回衛星のどちらでも利用可能である。しか し, 現在や近い将来に航空管制で使用されものとし て静止衛星を仮定する。インマルサット第 3 世代衛 星や運輸多目的衛星 (MTSAT)では, グローバルビー ムとスポットビームの両方を備えている。グローバ ルビームを使用する場合, 航空機側で小型機でも使 用可能な低利得アンテナ(利得 : $0 \mathrm{dBi}$ )を用いると伝 送速度の上限は $1.2 \sim 2.4 \mathrm{kbps}(\mathrm{kbit} / \mathrm{sec})$ 程度と考えら れる。航空機側に低利得アンテナを使用した場合で も，伝送遅延時間を縮小し，かつ処理容量を向上さ せるためには伝送速度の増加や，スポットビームの 利用が必要である。このため, 衛星のスポットビー ムを利用するものと仮定した。

伝送シーケンスを Fig.6に示す。また, Fig.7 にポ ーリング方式 ADS での ADS レポート伝送のタイム チャートを示す。ADS レポート伝送においては，1 $\sim \mathrm{N}$ の各 AES 局当たりの ADS レポート伝送間隔 $\mathrm{T}_{\mathrm{AES}}$ 内で, 同一チャネルで異なる航空機に伝送され るADS レポートとの衝突を防ぎ, 互いに重ならない ようにするため, バースト信号長 $\mathrm{T}_{\mathrm{ADS}}$ とは別にガー ドタイム $\mathrm{T}_{\mathrm{G}}$ が設けられている。バースト信号長は伝 送速度により異なる。また，ガードタイムはスポッ トビームを使用する場合, 一般に, GES からスポッ トビーム内の AES までの往復距離の差の最大值か ら求められるため，0.04秒と仮定した。なお，ポー リング方式 ADS においても現用 ADS 同様のバース 卜信号長と仮定した。 


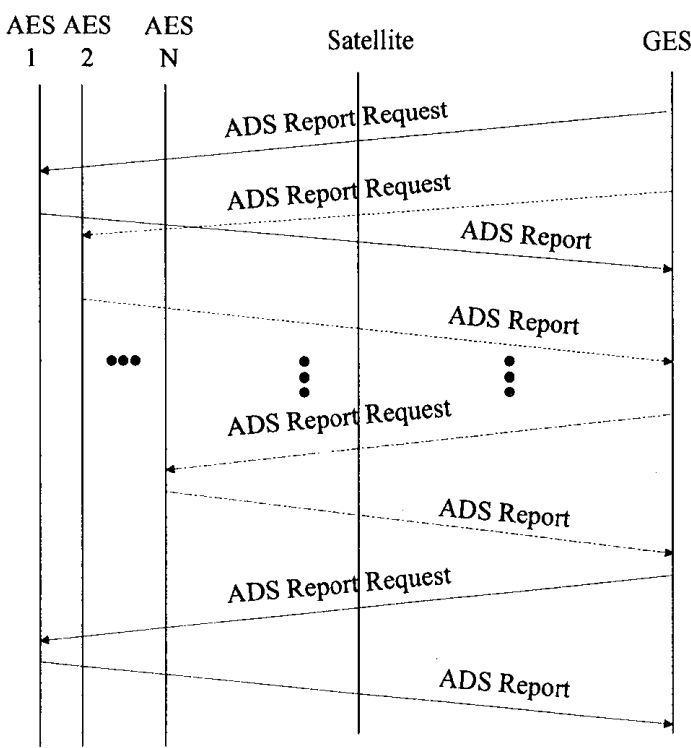

Fig.6 Transmission Sequence of Polling ADS
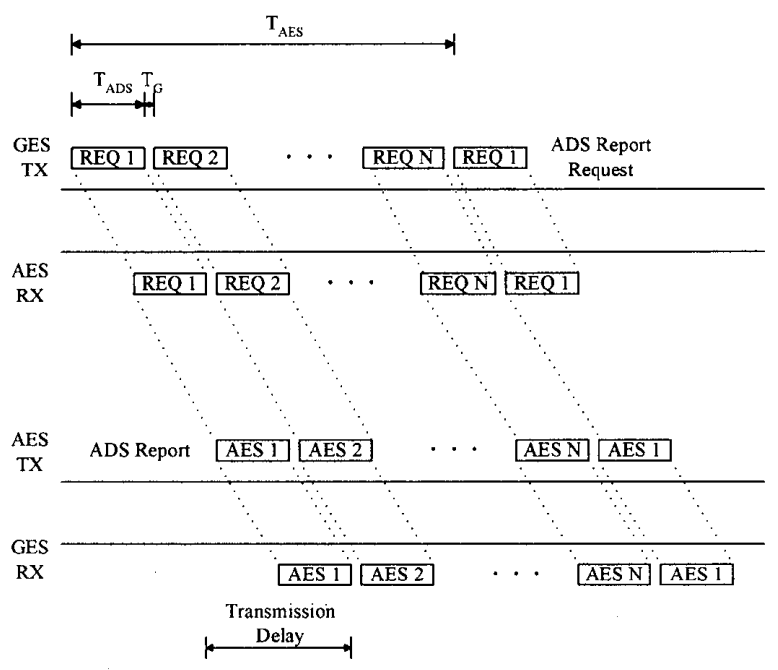

Fig.7 Transmission Flow in Polling ADS

以上のように, ポーリング方式 ADS では, 簡易な プロトコルで，現用 ADS に比べ，伝送遅延時閒を小 さくできる。しかし，ADSレポート伝送チャネル 1 回線で扱える AES 数は限られるため, AES 数が増 加すると回線数を複数にする必要がある。またデ一 夕通信の伝送速度が増加した場合には，ガードタイ ムが 1 回線で扱うことのできるAES 数に与える影響

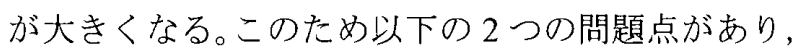
これらの影響を小さくする必要があった。

1. ADS レポートの送信回線数と同数の ADS レポー 卜送信要求伝送用回線を必要とする。

2. ADS レポート送信要求の伝送と ADS レポートの 伝送両方を考慮し, 衛星〜 AES 間の往復分のガード タイムを必要とする。

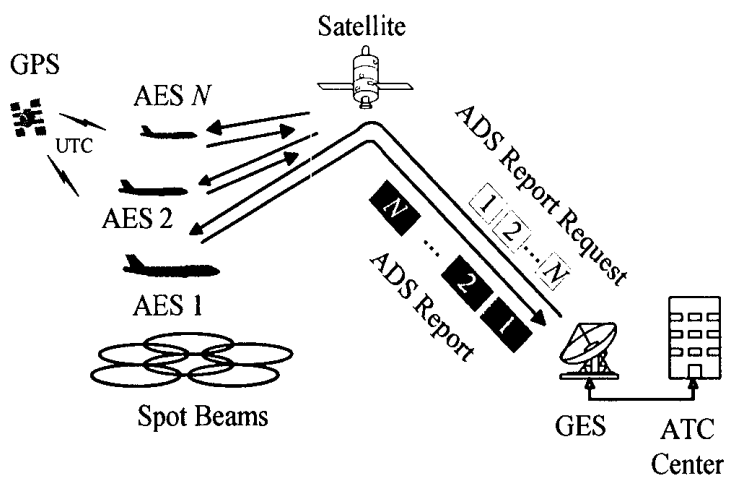

Fig.8 Concept of Self-synchronized ADS

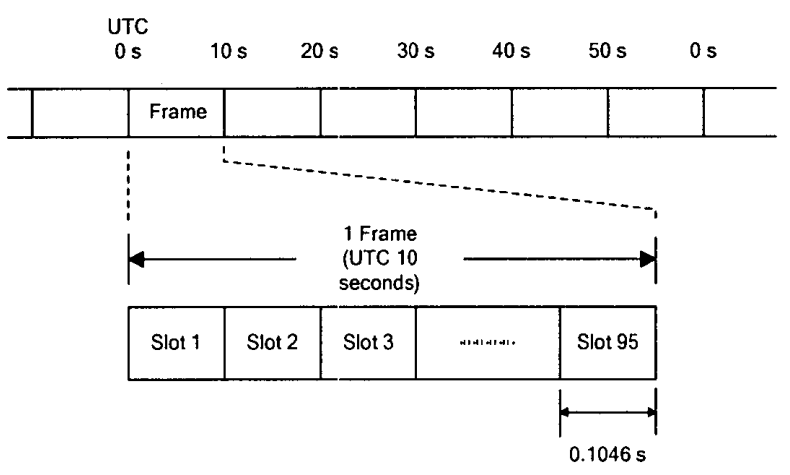

Fig.9 Slot Structure for ADS Report Transmission

(l0.5kbps)

\section{3 自己同期方式 ADS}

前節の問題点を改良した自己同期方式 ADS の概 念図をFig.8 に示す。この方式は, 地上から ADSレ ポート送信要求を各 AES に送信し, ADS レポート を伝送する送信スロットを指定する。AES は GPS による時刻によってUTCに同期し，指定された送信 スロットでADS レポートを送信する。なお, 自己同 期方式 ADS でも，現用 ADS 及びポーリング方式 ADS 同様にログオンが実施されているものとした。

この方式では, 各 AESに別々の送信スロットが割 り当てられるよう, 䶂数の送信スロットで1つのフ レームを構築し，UTCを基準とした一定周期で，こ のフレームの通信を行う。これにより，各 AES から 一定間隔の ADS レポートを伝送できる。なお，1つ のフレーム内のスロット数は, 送信周期, バースト 信号長, ガードタイムにより決定されるものとした。

例として, 10.5kbps の送信スロットを Fig.9 に示す。 ADS レポートが， 10 秒周期で各 AESに送信スロッ トが割り当てられる煋合, 送信スロット幅はバース ト信号長である 0.0846 秒とガードタイムである 0.02 秒の和である 0.1046 秒のため, スロット数は 95 に 設定できる。

ADS レポート送信要求は ADS 開始時に一度だけ 


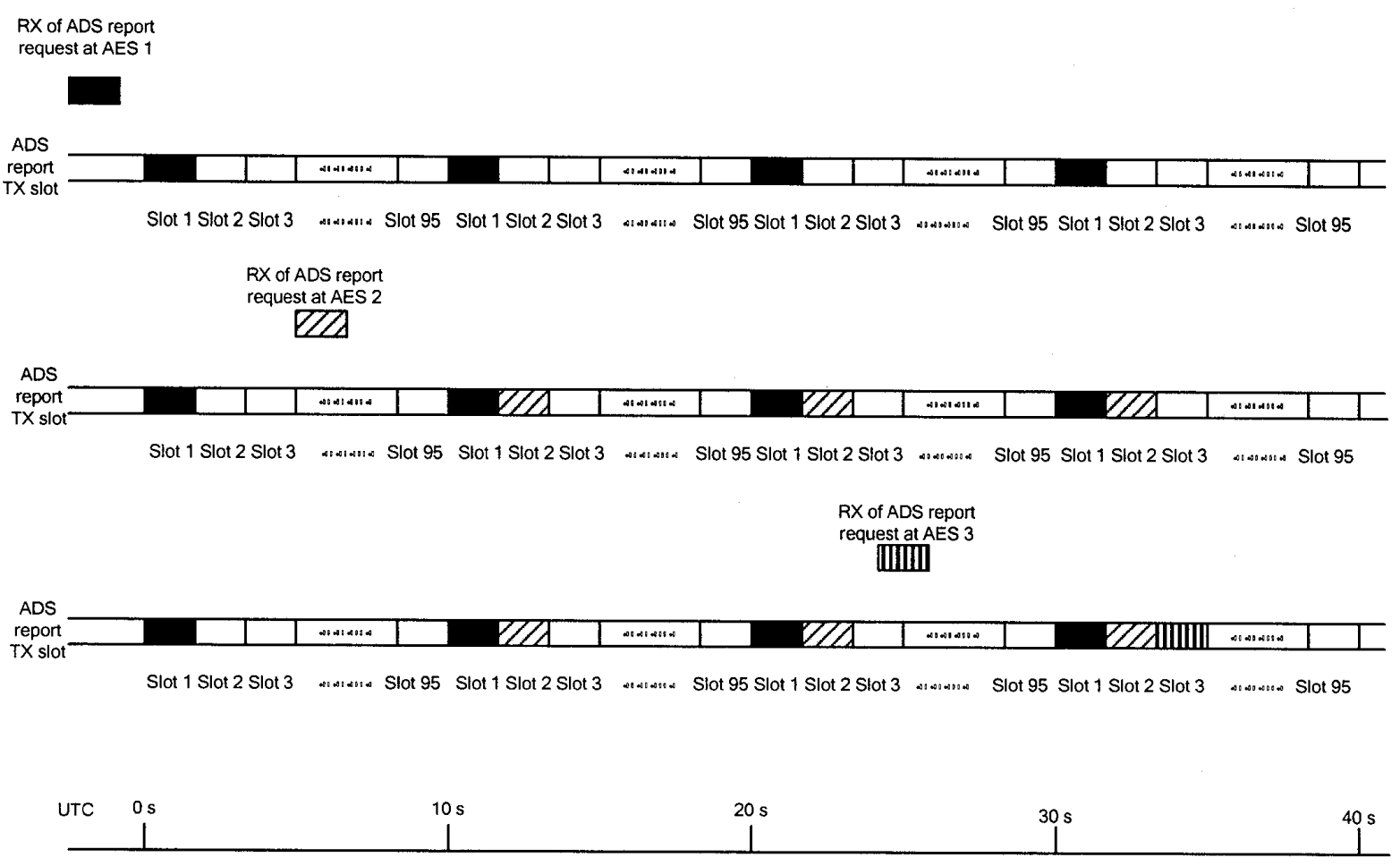

Fig.10 Slot Allocation in ADS Report Transmissions (10.5kbps)

送信し，送信スロット番号を割り当てている。この ため, ADS レポート送信要求の伝送チャネル数は, 複数の ADS レポートの伝送チャネルで共用できる。 ADS レポートの伝送チャネルと同数の ADS レポー 卜送信要求用伝送チャネルは不要である。ガードタ イムも, ADS レポートの伝送のみを考虑すればよい ため, ポーリング方式 ADS の半分でよい。すなわち, ポーリング方式 ADS のガードタイムを 0.04 秒と仮 定すると, 自己同期方式 ADS のガードタイムは 0.02 秒でよい。なお，自己同期方式 ADS は, 現用 ADS, 及びポーリング方式 ADS 同様のバースト信号長と 仮定した。

$10.5 \mathrm{kbps}$ の送信スロットの割り当て状態を Fig. 10 に示す。各 AES における割り当て状態は以下のとお りである。まず, AES1 はAES1 宛の ADSレポート 送信要求を受信する。その後, AES は決められたス ロット(例えばslot1)で定期的にADSレポートを送信 する。次に AES2 宛の ADS レポート送信要求を受信 した場合, AES1のADS レポート送信のための予約 済スロット(slot1)以外のスロット(例えば slot2)を予 約して，伝送間隔の周期である 10 秒毎に定期的に AES2 の ADS レポートを送信する。AES3 以下は, これと同様にして通信を繰り返す。なお，実際の運 用環境では各 AES と GES の間の通信開始時刻はラ ンダムになる。このため, 各 AES からの ADS レポ 一ト送信要求はランダムに発生するものと考える。

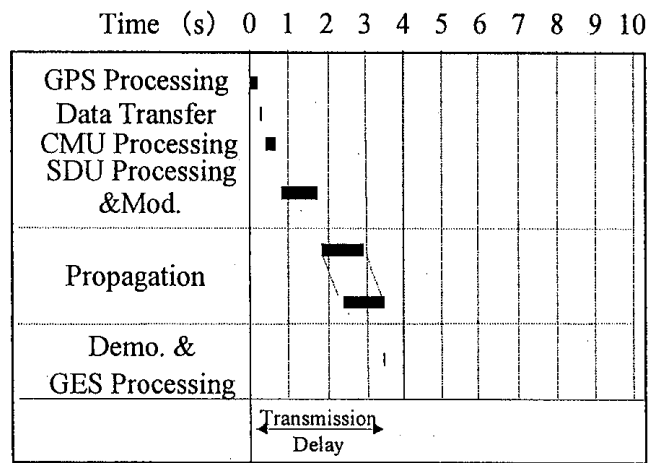

Fig. 11 Time Chart for ADS Report Transmission (0.6kbps)

\section{3. 伝送性能の解析}

\section{1 伝送遅延時間}

ADS レポートの伝送における自己同期方式 ADS の伝送遅延時間(Transmission Delay)のタイムチャー 卜例を Fig.11 に示す。伝送データ長は, Fig.2 に示す

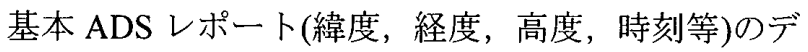
一タ長 1loctet を, R チャネルのデータフォーマット を利用して送信するものと仮定した。また，ポーリ ング方式 ADS，及び自己同期方式 ADS の場合， R チャネルの利用により定期的な通信を繰り返すこと ができるものと仮定した。このため，Rチャネルは 1SUとする。

Fig.11のとおり，0.6kbps の場合，伝送遅延時間は 3.5 秒であった。Table 1 にタイムチャートをもとに した各伝送速度毎の伝送遅延時間をまとめた。ポー 
リング方式 ADS 及び自己同期方式 $\operatorname{ADS}$ の伝送遅延 時間は原理上同一で，非常に小さいことがわかる。

\section{2 スループット}

伝送間隔を 10 秒とした場合の，ポーリング方式 ADS と自己同期方式ADSにおけるバースト信号長, ガードタイム, 1 チャネルあたりに送信可能な最大 AES 数について, 伝送速度毎に Table 2 にまとめた。 ポーリング方式 ADS や自己同期方式 ADS は，プロ トコルの性質上, AES 数によらずチャネルの伝送遅 延時間は一定となる。

スループットを ADS レポートのバースト信号が 回線を占有する時間率 $(\%)$ と定義すると，伝送間隔， バースト信号長, AES 数との関係は, 理論的に次の (1)式で表される。

$$
G=\frac{L \times N}{T} \times 100 \text { e }(\%)
$$

( $L:$ バースト信号長, $N: \mathrm{AES}$ 数， $T$ :伝送間隔,

$$
G: \text { スループット) }
$$

よって, Table 2 における 1 チャネルあたりの送信 可能な AES 数に基づき, ポーリング方式ADS では, 伝送速度 4.8kbps の場合スループットは最大約 75\%, 伝送速度 $10.5 \mathrm{kbps}$ の場合スループットは最大約 $68 \%$ と計算できる。自己同期方式 ADS では，伝送速度 $4.8 \mathrm{kbps}$ の場合スループットは最大約 $86 \%$, 伝送速度 $10.5 \mathrm{kbps}$ の場合スループットは最大約 $80 \%$ と計算で きる。これより，自己同期方式 ADS では，ポーリン グ方式 ADS に比べ，処理できる AES 数やスループ ットが 2 割程度増加していると推定される。

\subsection{ADS レポート損失率}

ADS レポートの損失を ADS レポート送信要求は 送信したが，ADS レポートが GES に正しく到着し ない場合と定義した。このとき，ポーリング方式 ADSにおけるADSレポート損失は, ADSレポート 送信要求が AES に正しく届かない時と, ADS レポ
ート送信要求は AES に正しく届くが ADS レポート は GES に正しく届かない時の和と考えられる。GES から AES に伝送するフォワード回線において, $M$ ビ ットの情報データを持つ ADS レポート送信要求が AES に正しく届かない割合 $P_{R Q}$ は, 以下の(2)式で表 される。

$$
\begin{gathered}
P_{R Q}=P_{f U W}\left[1-\left(1-P_{f b}\right)^{M}\right]+\left(1-P_{f U W}\right) \quad(2) \\
P_{f U W}: \text { ユニークワード検出確率(フォワード回線) } \\
P_{f b}: \text { ビット誤り率(フォワード回線) }
\end{gathered}
$$

また AESから GES に伝送するリターン回線にお いて $N$ ビットの情報データを持つ ADS レポートが 正しく届かない割合 $P_{R E P}$ は，(3)式で表される。

$$
\begin{gathered}
P_{R E P}=P_{r U W}\left[1-\left(1-P_{r b}\right)^{N}\right]+\left(1-P_{r U W}\right) \\
P_{r U W}: \text { ユニークワード検出確率(リターン回線) } \\
P_{r b} \text { :ビット誤り率(リターン回線) }
\end{gathered}
$$

\begin{tabular}{|c|c|c|}
\hline \multirow{2}{*}{$\begin{array}{c}\text { Channel Rate } \\
\text { (kbps) }\end{array}$} & \multicolumn{2}{|c|}{ Estimated Transmission Delay (s) } \\
\hline & $\begin{array}{l}\text { Polling } \\
\text { ADS }\end{array}$ & $\begin{array}{c}\text { Self-synchronized } \\
\text { ADS }\end{array}$ \\
\hline 0.6 & \multicolumn{2}{|r|}{3.5} \\
\hline 1.2 & \multicolumn{2}{|r|}{2.0} \\
\hline 2.4 & \multicolumn{2}{|r|}{1.3} \\
\hline 4.8 & \multicolumn{2}{|r|}{1.0} \\
\hline 10.5 & \multicolumn{2}{|r|}{0.6} \\
\hline
\end{tabular}

よってこのときの.ADS レポート損失の割合(以 下，ADS レポート損失率) $P_{A D S}$ は(4)式で表される。

\begin{tabular}{|c|c|c|c|c|c|}
\hline \multirow{2}{*}{$\begin{array}{c}\text { Channel Rate } \\
\text { (kbps) }\end{array}$} & \multirow{2}{*}{$\begin{array}{l}\text { Burst Length } \\
\mathrm{T}_{\mathrm{ADS}}(\mathrm{s})\end{array}$} & \multicolumn{2}{|c|}{ Polling ADS } & \multicolumn{2}{|c|}{ Self-synchronized ADS } \\
\hline & & $\begin{array}{c}\text { Guard Time } \\
\mathrm{T}_{\mathrm{G}} \quad(\mathrm{s})\end{array}$ & $\begin{array}{l}\text { Number of AES } \\
\text { for one channel }\end{array}$ & $\begin{array}{c}\text { Guard Time } \\
\mathrm{T}_{\mathrm{G}} \quad(\mathrm{s})\end{array}$ & $\begin{array}{l}\text { Number of AES } \\
\text { for one channel }\end{array}$ \\
\hline 0.6 & 0.96 & \multirow{5}{*}{0.04} & 10 & \multirow{5}{*}{0.02} & 10 \\
\hline 1.2 & 0.46 & & 20 & & 20 \\
\hline 2.4 & 0.21 & & 40 & & 43 \\
\hline 4.8 & 0.1269 & & 59 & & 68 \\
\hline 10.5 & 0.0846 & & 80 & & 95 \\
\hline
\end{tabular}

$$
P_{A D S}=P_{R Q}+\left(1-P_{R Q}\right) P_{R E P}
$$

一方，自己同期方式ＡDS では，ADS レポート送 信要求は最初だけ必要なため, ADSレポート損失率

Table 1 Estimated Transmission Delay

Table 2 Number of AES for one channel 
はリターン回線で ADS レポートが GES に正しく届 かない割合とほぼ等しいと考えられる。このため， $P_{A D S}$ は，以下の(5)式で表せる。

$$
P_{A D S} \approx P_{R E P}
$$

Fig.12 に，(4)，(5)式から求めた ADS レポート損 失率とビット誤り率 $P_{f b}, P_{r b}$ との関係を示す。なお, ADS レポート送信要求と ADS レポートのデータフ オーマット及びバースト信号フォーマットは同一と した。ポーリング方式 $\mathrm{ADS}$ の場合, $P_{f b}$ と $P_{r b}$ が $10^{-5}$ のときの $P_{A D S}$ は $3 \times 10^{-3}$ であるが, 自己同期方式 $\mathrm{ADS}$ の場合は $P_{r b}$ が $10^{-5}$ のときの $P_{A D S}$ は $1.5 \times 10^{-3}$ と推定 できる。

\section{4. シミュレーション}

\section{1 概要}

航空衛星通信における通信性能の劣化は，航空管 制に大きな影響を与える可能性を有する。航空衛星 通信ネットワークにおける通信性能が簡単なモデル であれば，待ち行列理論 ${ }^{(7)}$ を用いて理論的に解析で きる。しかし，実際のネットワークは複雑であるた め，通信プロトコルモデルを利用した計算機シミュ レーションを利用する方法が一般的な解析手法であ る。通信プロトコルを正確にモデル化してシミュレ ーションを行うことにより，許容できない通信性能 の劣化が起こる通信条件や，1回線当たりの取扱い 機数等をあらかじめ定量的に把握し，実際に起こり うる様々な通信トラフィック条件に対する通信性能 を予測できる。

当所では，ICAO AMSS SARPs に基づく航空衛星

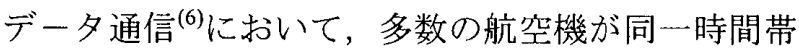
に通信を行う場合の通信性能を検証するための計算 機シミュレータを有している。計算機シミュレータ は，プロトコルシミュレータ OPNET(米国 MIL3 社 製) と，航空衛星通信評価用プロトコルモデル ASET(米国 Mayflower 社製)を一部改造し，組み合わ せている。ASET は, ICAO $の$ AMSS SARPs に適合 したデータ通信プロトコルに対応している。MTSAT やインマルサットの衛星による航空衛星データ通信 はこの通信プロトコルに基づき，主として伝送速度 $0.6 \mathrm{kbps}$ と $10.5 \mathrm{kbps}$ で行われており，これまでにも 伝送遅延時間や伝送効率，容量等の通信性能の解析 を行ってきた。

しかし，自己同期方式 ADS は当所が提案する新た な方式であり，ICAO AMSS SARPsには準拠してい ない。このため，現用シミュレータとプロトコルが 異なり，現用シミュレータのままでは，自己同期方

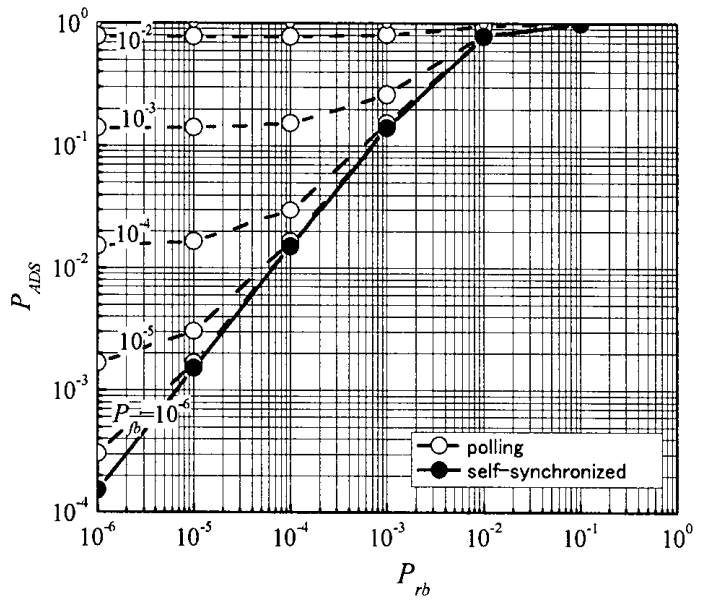

Fig.12 ADS Report Loss Rate

式 ADS の伝送特性解析はできない。このため，自己 同期方式 ADS の伝送特性をシミュレーション解析 できるよう,自己同期方式 ADS のプロトコルモデル をASETに組込む改修を行い，現用 ADS と自己同期 方式 ADS の伝送性能を比較検討した。

\section{2 方法}

通信トラフィックモデルでは，伝送データ長，伝 送間隔，伝送形態(周期的またはランダム)等の通信 トラフィックモデルとなる条件を設定する。ASET における計算機シミュレーションは，その設定に従 い，通信シミュレーションソフトウェアを用いて高 速に実行され，伝送遅延時間，スループット等の通 信性能が出力される。通信トラフィックモデルとし ては，例えば「100の AESが 10 octet のデータを指 数分布に従うランダムな伝送間隔で伝送する。よい う内容で設定される。なお，ASET でのネットワー クは，AES， GES及び衛星(Satellite)から構築されて おり，設定可能な AES 数は最大 400 である。

自己同期方式 ADS のシミュレーションを実現す るため，現用の航空衛星通信モデルにおける 8 秒毎 のスーパフレームと呼ばれるスロットを用いた。こ のスロットを用いることで, 必ず GPSによる時刻同 期ができていると仮定し, 定期的に ADS 伝送するこ とにした。よって, ADS レポートの伝送間隔は 8 秒 と仮定される。伝送データ長は, 基本 ADSレポート (緯度, 経度, 高度, 時刻等)のデー夕長 11 octet に, 各種通信制御用ヘッダが付加されていると仮定し， 223octet とした。他の設定は以下のとおりである。

*伝送速度 : $0.6 \mathrm{kbps}, 10.5 \mathrm{kbps}$

*シミュレーション回数 : 5 回

*AES : 10〜200 まで 10 機毎 


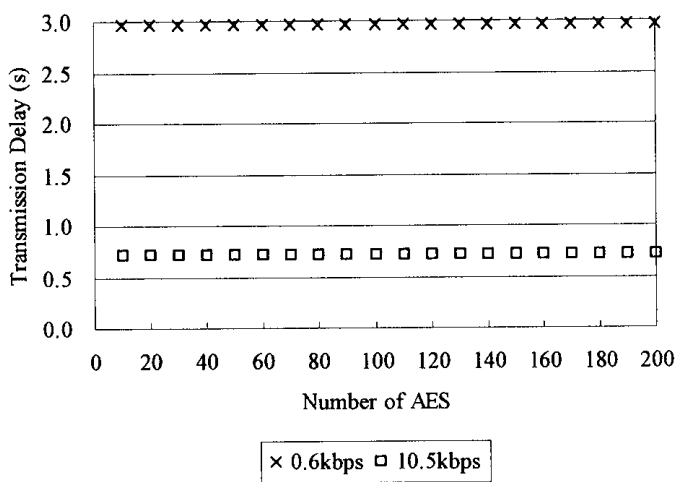

Fig.13 Transmission Delay of AES per Channel in the case of Self-synchronized ADS

また，比較対象として，現用の航空衛星通信モデ ルにおけるシミュレーションを同一の伝送データ長, 伝送速度, シミュレーション回数で実施した。伝送 間隔は 32 秒, AES は 200 まで可変とした。

現用の航空衛星通信モデルにおけるシミュレーシ ヨンは, 前章に述べたとおり, ATNを仮定している。 このため; 位置データ相当の伝送には Tチャネルを 用いている。

\section{3 検討結果}

前節の設定に基づき, ADS レポートを定期的に伝 送したときの自己同期方式 ADS の伝送遅延時間を 求めた。

す心゙てのシミュレーション事例において, AES 数 によらず，5回とも同一の結果が確認された。Fig.13 に自己同期方式 ADS の航空衛星通信モデルにおけ る $\mathrm{e}$ 伝送速度毎の各 AES と伝送遅延時間 95\%值のシ ミュレーション結果の 5 回平均值を示す。 $0.6 \mathrm{kbps}$ の場合の伝送遅延時間は 2.975 秒, $10.5 \mathrm{kbps}$ の場合 の伝送遅延時間は 0.721 秒であった。

Fig.14に現用ADS の航空衛星通信モデルにおける 伝送速度毎の各 AES と伝送遅延時閒 95\%值のシミ ュレーション結果の 5 回平均値を示す。Fig.15 は, AES10 機の場合の自己同期方式 ADS, 及び現用 ADS の伝送遅延時間 95\%值のシミュレーション例として， 適当な 60 秒間を抽出した結果である。なお, Fig. 15 において, 現用 ADS で 0.6kbps の場合は, 数千秒と 非常に大きな伝送遅延時間となったため含まれてい ない。

Fig.14 に示すとおり，伝送間隔が 32 秒であれば， $0.6 \mathrm{kbps}$ の場合 AES が 2 機まで, $10.5 \mathrm{kbps} の$ 場合 AES が 49 機までしか許容值(60 秒)を満たさない。また, Fig.15 に示すとおり, 現用 ADS は, そのプロトコル 上，伝送遅延時間がばらつき，值も大きい傾向があ

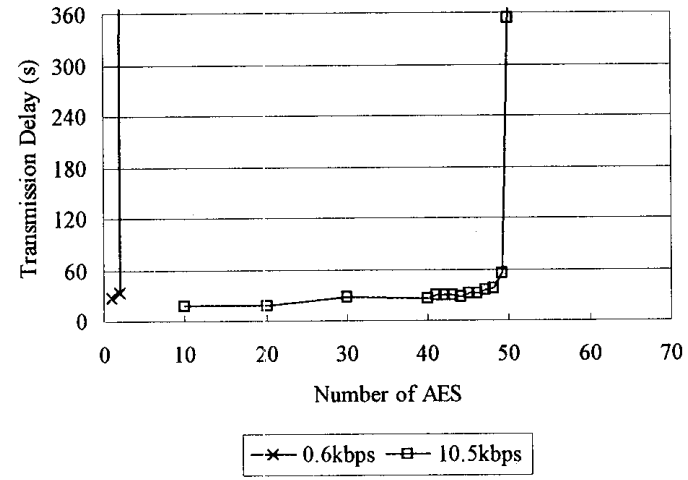

Fig.14 Transmission Delay of AES per Channel in the case of Current ADS

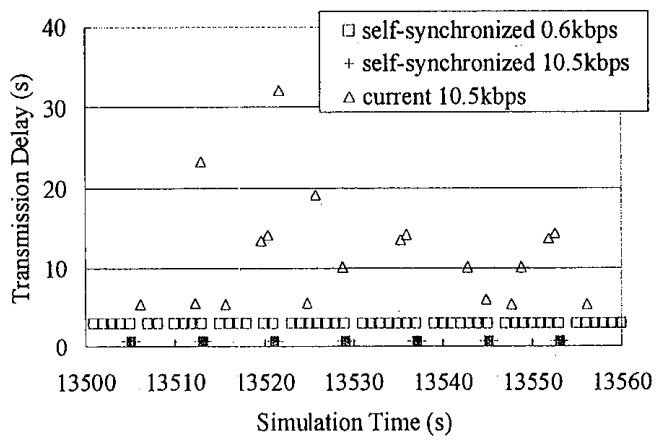

Fig.15 Example of Transmission Delay

ることがわかる。これに対し，自己同期方式 ADS では, 数秒単位での伝送が可能となり, 短い伝送間 隔での監視が期待できる。

伝送性能解析における自己同期方式 ADS の伝送 遅延時間は $0.6 \mathrm{kbps}$ で 3.5 秒， $10.5 \mathrm{kbps}$ で 0.6 秒であ った。これに対し，シミュレーションでは， $0.6 \mathrm{kbps}$ の場合で 2.975 秒, $10.5 \mathrm{kbps}$ の場合で 0.721 秒である。 $0.6 \mathrm{kbps}$ の場合の伝送遅延時間はシミュレーション のほうが短いが， $10.5 \mathrm{kbps}$ の伝送遅延時間はシミュ レーションの場合のほうが若千長かった。このよう に，自己同期方式 ADS の場合，伝送遅延時間は AES 数によらず一定で，非常に短いことが確認できた。

伝送性能解析は，以前当所で実施したハードウェ ア製作に基づくため，現実により近い性能予測值と 考える。自己同期方式 ADS のプロトコルモデル部分 は性能解析とシミュレーションで同一であり，シミ ユレーション実現のために元々の ASETを利用して いる。このことから，伀送性能解析とシミュレーシ ヨンの伝送遅延時間が異なった原因の一つとして, 元々の ASET の設定値の一部が製作したハードウェ アの值と異なる可能性等が考えられる。

\section{6. むすび}


ポーリング方式 ADS の問題点を改善できる自己 同期方式ADSについて検討した。自己同期方式ADS は, AES 毎に別々の送信スロットを割り当て, 複数 の送信スロットで 1 つのフレームを構築し，UTC を基準とした一定周期で $\mathrm{AES}$ から $\mathrm{ADS} レ$ ポートを 伝送できる。この結果, 自己同期方式 ADS はポーリ ング方式 ADS よりも, ADS レポート送信要求伝送 用回線数を減少でき，1 チャネル当たりの AES 数の 伝送遅延時間を改善できる可能性があることがわか った。また，ADS レポート損失率も半分に改善でき る可能性があることもわかった。さらに，現用 ADS 用シミュレーションに機能追加する改修を施し, シ ミュレーションによりその実行状況を確認した。こ の結果, 伝送遅延時閒は AES 数によらず一定であり, 最大でも 3 秒程度と非常に短い伝送遅延時間である ことが確認できた。今後は，自己同期方式 ADSを， より高速化し, 数多くの AES に対応できる方策を検 討寸る予定である。なお自己同期方式 ADS は，時刻 同期に GPS の利用が前提であるため, GPS が利用で きない場合での, ポーリング方式 ADS との併用策等 を検討する必要があると考える。

\section{参考文献}

（1）石出他:"衛星利用 ADS の伝送特性改善につい て”,第 2 回電子航法研究所発表会, 2002.6

（2）石出他:"ポーリング方式 ADS の伝送特性”,電子 情報通信学会総合大会 B-2-38,2003.3

（3）石出:"衛星を用いた自己同期型 ADS の概念につ いて”,電子情報通信学会技術報告 SANE,2003.7

（4）住谷他:"Concept of Self- synchronized ADS using Satellite", NexSAT $3^{\text {rd }}$ Steering Group Meeting in Eurocontrol, Brussels, WP3, 2003.10

(5) 板野他: “航空通信網(ATN) の研究”, 電子航法研 究所報告, No.100, 2003.2

（6）石出他：“自動従属監視(ADS)実験システムの開 発と実験”，電子情報通信学会論文誌(B-II), Vol.J78-B-II, No.5, pp.366-373, 1995.5

（7）北岡正敏 : “情報処理試験のための確率・統計と 待ち行列理論”, 産業図書, 1994

\section{謝辞}

本研究の実施に際し，ご協力いただきました関係 各位に感謝申し上げます。

\section{質疑応答}

浪江 宏宗(防衛大学校)：

ADS の混雑現況はどのようでありますか。
住谷 泰人(電子航法研究所)：

現用 ADS の伝送間隔である約 27 分は, 現在の洋 上の空域の混雑状況に適した伝送間隔で運用がな されています。なお, 従来は約 16 分の伝送間隔で 運用されていました。このため, 今後, 利用航空 機数が増減した場合には, その状況に応じて変化 する可能性があります。例えば，洋上ではなく， 空港周辺等に多数の航空機が存在し, 混雑する空 域で利用する場合には，より小さな伝送間隔を用 いて，監視性能を向上させる必要があります。 